\title{
Non Invasive Ventilation a Threat for Health Care Workers in COVID-19 Outbreak
}

\author{
Yaser Saeid $^{\circledR}$, Mohammad Ali Sheikh Beig ${ }^{2}$, Malihe Sadat Moayed $^{1 *(}$ \\ ${ }^{1}$ Trauma Research Center, Faculty of Nursing, Baqiyatallah University of Medical Sciences, Tehran, Iran \\ ${ }^{2}$ Nanobiotechnology Atherosclerosis Research Center, Baqiyatallah University of Medical Sciences, Tehran, Iran
}

\begin{abstract}
*Corresponding Author: Malihe Sadat Moayed, Ph.D., Assistant Professor, Trauma Research Center, Faculty of Nursing, Baqiyatallah University of Medical Sciences, Tehran, Iran. Tell: +98-21-87555495, Fax: +98-21-87555480, Email: msmoayed@gmail.com
\end{abstract}

Received February 16, 2021; Accepted April 6, 2021; Online Published April 21, 2021

\section{Dear Editor,}

Coronavirus disease (COVID-19) is a pandemic disease with unknown process and treatment that has affected the population worldwide. Patients with COVID-19 need respiratory support following acute respiratory failure. ${ }^{1}$ According to severe acute respiratory failure and its symptoms, performing respiratory support using high flow nasal cannula (HFNC), non-invasive mechanical ventilation (NIV), and finally, intubation and the onset of invasive mechanical ventilation will be indicated. ${ }^{2}$

The oxygen therapy and respiratory support with proper technique in acute respiratory failure syndrome or acute respiratory distress syndrome with less intensity could have a significant role in treating tissue hypoxia. ${ }^{3}$ One of the effective measures in respiratory support of COVID-19 patients before tracheal intubation and the onset of invasive mechanical ventilation is "non-invasive mechanical ventilation," which provides positive airway pressure for respiratory support without invasive intubation.

One of the positive consequences of NIV is the appropriate effectiveness in the management of acute respiratory failure, reduction of mortality, and ventilatordependent pneumonia.

However, NIV for COVID-19 patients is one of the major concerns for health care workers (HCWs) due to the increased chance of spreading the virus and subsequent infection. ${ }^{3}$ Providing optimal conditions for safe care is essential to maintain the health of medical staff in NIV. ${ }^{4}$ To reduce the risk of HCW the patient should be isolated under NIV and hospitalized in a negative pressure environment. HCWs must have all considerations related to personal protection; wearing a mask N95, shield, isolation gown, and gloves must be observed.

Making the correct settings, using the right interface such as non-vented full mask, Helmet, and oronasal mask can effectively reduce the emission of airborne particles. Proper regulation and monitoring of inspiratory pressure less than $20 \mathrm{~cm} \mathrm{H} \mathrm{H}_{2} \mathrm{O}$ can also reduce the chances of particulate matter release.

A vented mask in NIV is not recommended due to the high risk of spreading infection. If HCWs have to use it, its exhalation outlets should be sealed with glue, and the exhalation ports should be equipped with antibacterial and viral filters (Figure 1). Therefore, the use of HEPA or HMEF filter during NIV is necessary to curb the risk of spreading infection from the patient to the environment and others. Therefore, although NIV is effective in managing COVID-19 patients, at the same time, due to its role in the spread of infection, being careless could lead to the severe outspreading of the disease. The safety of employees should be maintained by taking effective support measures by reducing the chances of emitting particulate matter and environmental pollution. Providing specialized training and using appropriate personal protective equipment can be helpful in this regard and increase safe care in the treatment staff and improve patient outcomes.

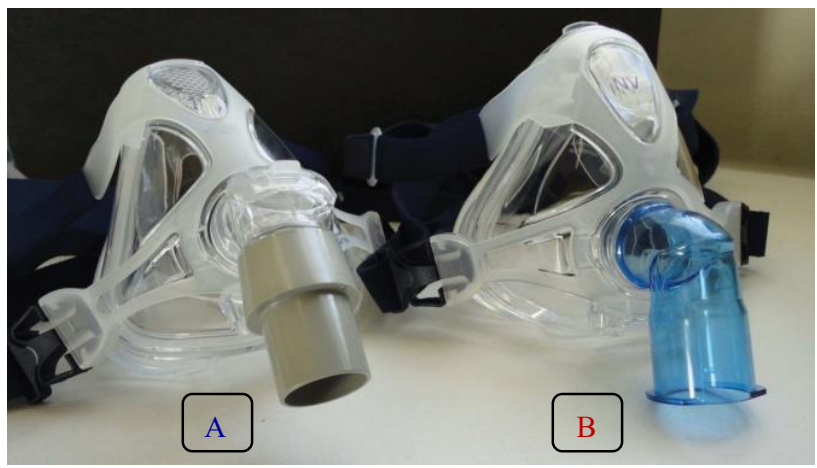

Figure 1. The vented mask vs. non-vented mask has an exhalation port on the mask. A: Vented mask B: Non vented mask

Copyright $\odot 2021$ The Author(s). This is an open-access article distributed under the terms of the Creative Commons Attribution License (http:// creativecommons.org/licenses/by/4.0), which permits unrestricted use, distribution, and reproduction in any medium, provided the original work is properly cited. 
Authors' Contributions

All authors contributed equally to this study.

\section{Conflict of Interest Disclosures}

The authors declared no conflicts of interest concerning the authorship and publication of this article.

\section{Ethical Approval}

Not applicable.

\section{Reference}

1. VardhanaSA, WolchokJD. The many faces of the anti-COVID immune response. J Exp Med. 2020;217(6):e20200678. doi:10.1084/jem.20200678.
2. Ñamendys-Silva SA. Respiratory support for patients with COVID-19 infection. Lancet Respir Med. 2020;8(4):e18. doi:10.1016/s2213-2600(20)30110-7.

3. Tabashi S, Mirkheshti A, Dahi M, et al. Supplemental oxygen therapy and non-invasive ventilation in corona virus disease (COVID-19). J Cell Mol Anesth. 2020;5(1):27-31. doi:10.22037/jcma.v5i1.29689.

4. Simonds AK, Hanak A, Chatwin M, et al. Evaluation of droplet dispersion during non-invasive ventilation, oxygen therapy, nebuliser treatment and chest physiotherapy in clinical practice: implications for management of pandemic influenza and other airborne infections. Health Technol Assess. 2010;14(46):131-172. doi:10.3310/hta14460-02. 